\title{
Cultural Aspects of a Patient's Symptomatology: A Case Report
}

Theresa M. Miskimen, M.D.

University of Medicine and Dentistry of New Jersey, Newark, New Jersey

Follow this and additional works at: https://jdc.jefferson.edu/jeffjpsychiatry

Part of the Psychiatry Commons

Let us know how access to this document benefits you

\author{
Recommended Citation \\ Miskimen, M.D., Theresa M. (1993) "Cultural Aspects of a Patient's Symptomatology: A Case Report," \\ Jefferson Journal of Psychiatry. Vol. 11 : Iss. 1 , Article 7. \\ DOI: https://doi.org/10.29046/JJP.011.1.010 \\ Available at: https://jdc.jefferson.edu/jeffjpsychiatry/vol11/iss1/7
}

This Article is brought to you for free and open access by the Jefferson Digital Commons. The Jefferson Digital Commons is a service of Thomas Jefferson University's Center for Teaching and Learning (CTL). The Commons is a showcase for Jefferson books and journals, peer-reviewed scholarly publications, unique historical collections from the University archives, and teaching tools. The Jefferson Digital Commons allows researchers and interested readers anywhere in the world to learn about and keep up to date with Jefferson scholarship. This article has been accepted for inclusion in Jefferson Journal of Psychiatry by an authorized administrator of the Jefferson Digital Commons. For more information, please contact: JeffersonDigitalCommons@jefferson.edu. 


\title{
Cultural Aspects of a Patient's Symptomatology: A Case Report
}

\author{
Theresa M. Miskimen, M.D.
}

\begin{abstract}
Culture influences numerous aspects of human experience including behavior, beliefs, values and attitudes. A case report is presented emphasizing how cultural manifestations of a psychiatric illness may materially affect presentation of symptoms, illness perception, and explanatory model of illness of a patient. Cultural background is explored to offer improved rapport and patient care.
\end{abstract}

Traditions, customs and value systems accumulated over a number of generations, strongly influence behavioral patterns of a given society. Such cultural influences may affect a patient's presentation of symptoms, illness perception, and the explanatory model of illness when an individual seeks psychiatric treatment (1). The case report presented here underscores the influence culture exerts over a patient's presentation of psychiatric illness.

Spiritism among Latin Americans is a widespread belief transcending generations as a healing system since the end of the 19th century (2). An important aspect of this belief is its application to amelioration or cure of physical and mental ailments. In Puerto Rico, spiritism, whose origins can be traced to France, was incorporated as part of a charitable movement of the elite and evolved as a cultural pattern for a substantial portion of the population. Reports in the literature indicate that $36-60 \%$ of Puerto Ricans have visited spiritists at some point during their lives (2).

Spiritists are believed to serve as intermediaries (mediums) between this world and that of the spirits by contacting spirits and communicating with them in an effort to understand the nature of the problems of their clients. Spiritists emphasize the mediating action of fluids on personal well-being (3). Fluids are considered to be spiritual emanations surrounding the body and are derived from the innate spirit, spirits of the dead, and incarnate spirits close to the living. The fluids may be "sick or troubled" and are influenced by six phenomena that may lead to mental or physical illness. These include: (a) karma (situations from previous lifetimes that influence the present), (b) inexperienced mediums, (c) religious negligence (failure to perform prescribed rituals), (d) witchcraft, (e) obsession by spirits, and (f) the evil eye.

During treatment sessions, spiritists attempt to further explain the existence and nature of the mental or physical problem presented to them in a manner parallel to the medical explanatory model. The client is typically advised that the symptoms are a consequence of one or more of the six phenomena listed above. For example, an individual suffering an obsession by a spirit is under the influence of and subjected to 
that spirit's will, can suffer a headache or other symptoms should the spirit so desire. In this example, the headache is the presenting symptom and the explanatory model is that the symptom is present due to the influence and will of the spirit over the person experiencing the symptom.

Puerto Ricans utilize spiritism as a folk psychotherapy as well as an outlet for anxiety. Nevertheless, epidemiological and anthropological data suggest that those afflicted with psychiatric disorders do not rely solely on spiritists, but also make use of the mental health system (3). The consequence of this interaction is that psychiatrists encounter patients who might elicit an explanatory model based on spiritism's teachings.

\section{CASE REPORT}

The patient is a 24 year old single Hispanic Roman Catholic female with five children, ranging from 4 years to 2 months old. She speaks Spanish and has negligible knowledge of English. The patient was brought to a Psychiatric Emergency Service (PES) following uncontrollable agitation and threatening behavior toward family members. The patient lives alone with her children in the same apartment building as her mother and one of her sisters. On the day of admission, neighbors had complained of shouting coming from the patient's apartment. When the patient's mother and sister entered the apartment, the patient became increasingly agitated and verbally and physically threatening, finally threatening to hang herself if they did not leave. At that point, the mother summoned Emergency Medical Services (EMS) and the patient was transported to PES for further evaluation. The patient offered a chief complaint of "Me siento mal; estoy oyendo cosas y viendo cosas" (I feel bad; I am hearing and seeing things). The interview was conducted in Spanish after the patient was stabilized.

The patient was initially interviewed in four point restraints. She appeared to be her stated age and was dishevelled and tearful. She was alert and oriented to person, place and time. Her speech pattern was slow and non-spontaneous. The patient described her mood as "Me siento mal" (I feel bad), and her affect was depressed. Her thought process was logical and presented no circumstantiality or loosening of associations. The patient had suicidal ideations about hanging herself but denied homicidal ideations. She thought that her eldest child could read her mind and had been doing so for approximately a year. She also reported that, on the day she was admitted, she was receiving messages through the television and the radio but could not decipher these messages. She was also experiencing visual hallucinations in the form of a demon-like creature in her apartment. Her remote and recent memory were intact. Concentration and abstract thinking were poor. Judgment and insight of the patient were poor.

According to the patient's sister, her behavior had undergone marked change during the week prior to the admission. The patient was described as seclusive and aloof, her verbalization at times was not relevant to the topic of conversation, and she became irritable when confronted with her behavioral changes. 
The patient was placed in four point restraints upon arrival at the emergency room (ER) and was medicated with lorazepam $2 \mathrm{mg}$. intramuscularly, to control the agitated behavior. After the patient was stabilized, she described a feeling of sadness and uneasiness during the prior month and had considered hanging herself. The patient then stated that she had refrained from doing so because one of her children had read her mind and ordered her not to hang herself. The patient also remembered having the impression that she was "going to be sick." To her, this meant that she would be harassed by a demon-like spirit.

The patient stated that one of her children was also "possessed" by the demon-like spirit and that the spirit could travel back and forth, via an "electric current," between herself and the child. The patient described how the demon-like spirit could talk to her but that she was unable to understand its language, although it was apparent to her that it wanted to hurt the children and separate her from them. The patient had total recollection of the events prior to her transfer to PES and denied any loss of consciousness.

This was the patient's first psychiatric admission, although she had experienced auditory and visual hallucinations since her teenage years. She would hear voices "that came from the trees" calling her name and saw crosses in the sky. She was taken to see a spiritist who declared that all the symptoms were the product of the influence of a bad spirit. The spiritist's treatments, called "despojos" (removal of a spirit) consisted of trying to contact the spirit that was causing the problems and ordering it to cease harassing the patient. The patient felt that she was a helpless victim at the mercy of this spirit. Both patient and parents believed that only the spiritist could solve the problem. Before the treatment was completed, the patient eloped with a man with whom she had had a short-lived relationship characterized by physical and emotional abuse. This action was also thought to be directly manipulated by the obsessing spirit. The patient returned to her family and, because she continued to experience the same symptoms, was then sent to a Catholic spiritual retreat with the hope that the experience would benefit her condition. After attending the retreat and returning to her family, she continued to experience visual hallucinations including, for the first time, a hideous demon-like creature whom she believed was going to take her away. The patient was taken to a nearby community hospital where the doctor prescribed a tranquilizer (chlordiazepoxide). The medication only provided sedation without ridding the patient of the hallucinations, so compliance with follow up and medication was short-lived. The patient was brought back to the spiritist who indicated that the spirit could not be overcome and that she could no longer be of help. The patient continued to experience auditory and visual hallucinations, becoming so distressed that she attempted suicide. She was again brought back to the spiritist who tried additional treatment. Over time, the auditory and visual hallucinations began to decrease in frequency and finally disappeared. Nevertheless, the patient remained convinced that the spirit could and would continue to influence her life. She believed that this was the reason she felt uneasy going to church, why bad luck apparently followed her, why her child could read her 
mind and control her, and why she had been hallucinating prior to the present admission. It was her conviction that all was caused by the same spirit.

The patient was not on any medication regimen, had no known drug allergies, no history of medical problems, and denied any current or past history of alcohol or drug abuse. When she was initially evaluated in PES her vital signs were stable and the physical exam was unremarkable, except for cervical lymphadenopathy bilaterally. The neurological exam and laboratory data were unremarkable as well.

The patient was admitted to the psychiatric unit for further observation and treatment. During the initial 24 hour period of hospitalization, the patient was kept in four point restraints due to agitation. She voiced suicidal ideations, continued to be delusional and to experience visual and auditory hallucinations for which haloperidol $5 \mathrm{mgs}$ p.o. $\mathrm{q}$ hs and prn was prescribed in combination with lorazepam $2 \mathrm{mgs}$ on a prn basis. After the first 24 hours, the patient's condition improved so her restraints were removed. She was continued on a dose of haloperidol $5 \mathrm{mgs}$ p.o. q hs to which benztropine $1 \mathrm{mg}$ p.o. q hs was added because of extrapyramidal symptoms. By the third day, the patient no longer felt suicidal but continued to experience auditory and visual hallucinations. Haloperidol and benztropine were maintained at the same dosages and lorazepam was discontinued. On the fifth day she no longer complained of hallucinations but continued to have delusions that her daughter could read her mind and was possessed by the demon-like creature.

The delusions abated during the course of hospitalization and the patient was discharged after 12 days. The patient continued to believe that her child could read her mind and that the spirit would continue to influence her. There was no indication of suicidal nor homicidal ideations. The patient agreed to continue to take haloperidol and benztropine after her discharge and would comply with follow-up at the community mental health center. The patient also stated a desire for the help of a spiritist in her community while being treated at the mental health center. The patient's final diagnoses (4) were as follows:

AXIS I: Schizophrenia, Paranoid Type, Chronic with Acute Exacerbation

AXIS II: Deferred

AXIS III: None

AXIS IV: Psychosocial Stressors: unemployment, poverty, and being a single parent.

Severity: 4-Severe (enduring circumstances)

AXIS V: Current GAF:30. Highest GAF past year:50

\section{DISCUSSION}

People are born into specific cultures and are bombarded throughout their lives by the forces of tradition, customs and societal behavior patterns and value systems. These are handed down from generation to generation, creating recognizable cultural norms that impinge upon members of a given society. Spiritism, as a cultural 
manifestation, can influence various aspects of human experience. This case explores the influence that spiritism exerts on psychiatric symptomatic explanation, illness perception and explanatory model.

The Puerto Rican patient involved was treated by a spiritist before her first psychiatric intervention. The patient experienced auditory and visual hallucinations as an adolescent and was taken to a spiritist who diagnosed her condition as a consequence of obsession by a spirit. Spirits are classified according to an ascending hierarchy of moral development (5). Spirits at the lowest level are identified as ignorant and generally harmful to human beings. These spirits are believed to be able to control the thoughts and actions of an individual making him or her experience an obsession (6).

Spiritists attribute a patient's symptoms to actions of a spirit after which the patient generally incorporates their explanation into the model of illness. In this case, the patient attributed the symptoms presented at admission to a demon-like spirit. The symptoms can also be explained relative to the six phenomena, outlined above, that spiritists believe responsible for illness. One common denominator is that the basis for mental illness is believed to be external or displaced from the patient because it identifies the external spirit as the causative agent. In the process, the patient is freed from personal blame and guilt, and lacks control over what is happening to her. For this patient, although she did not experience guilt for being ill, the fact that she believed her illness to be caused by an external force prevented her from gaining any sense of control and contributed to her fatalistic point of view that her condition would never improve. This, in turn, could be the source of depressive and suicidal ideations. In her view, there was no hope because not even the spiritist could fully rid her of the problem-causing spirit. Even when the patient's condition improved with the medication, she was sure that the symptoms would recur because her illness was a direct result of the spirit within her and the spirit was not taking the medication.

The explanatory model also molded the way in which the patient and her family perceived her and her illness. During an interview with the mother, it was evident that there was increased family tolerance for the symptoms after the initial spiritist intervention. Her child's behavior was accepted as a consequence of this evil spirit and there was little that the patient could do to control the various symptoms. Having understood the origin of the symptoms, it became easier for the family to empathize with the patient and provide special care and understanding. This is particularly important because, among Hispanics, the family serves as a primary means of support and care giving (7).

Spiritism as a dimension of culture, could serve as a conduit of greater social acceptance of people with psychiatric symptoms (8). The symptoms presented reflect an explanatory model based on spiritists teachings in that the symptoms are caused by a spirit, not by the patient. Acceptance of these views would increase tolerance for patients and reduce the possibility of ostracism by the family.

If the patient's culturally influenced explanatory model is better understood, areas of impasse could be reviewed in light of that model and acted upon during 
treatment. In this case, the patient believed her symptoms to be caused by an external force, over which she had minimal control. She considered herself to be a victim and that, even if her condition improved, improvement would be short-lived. By allowing the patient to explain the nature of what she believed to be the problem, rapport was established and compliance with hospitalization treatment improved (1). The theory of chemical imbalance was explained so/as to help the patient understand her illness from a medical point of view. Medication was explained in terms of amelliorating the symptoms that she believed were caused by the influence of the spirit. The patient did not refuse medication during her hospital stay. It could be theorized that by integrating the patient's cultural beliefs in the medical explanatory model acceptance of medication and rapport were improved. It is important to remember that the patient's belief that she was obsessed by a spirit did not constitute a delusion but was an integral component of her culturally influenced explanatory model of illness. Understanding cultural influences can bridge transcultural aspects present in the doctor-patient relationship and as a consequence can also improve rapport. The patient's beliefs where also taken into consideration when her discharge from the hospital was planned. She was referred to the community mental health clinic, but seeking spiritual help was not discouraged. This flexible approach does not conflict with the explanatory model of illness plus there is a greater probability of compliance by the patient.

\section{CONCLUSION}

Kroll et al (9) point out, "religious beliefs and practices take an important and frequently central place in the lives of many of our patients." In this case history, the key practice is spiritism. In doing so, spiritism influenced the manner in which the patient explained her symptoms, how she perceived herself and her illness, and how her family interacted with her.

It was possible, through exploration of her cultural background, to understand the meaning the patient had allocated to her symptoms, her illness, and the influence it exerted over her. Rapport was established because the patient was able to communicate her concerns and fears about illness in her own terms. The patient was able to accept treatment during her hospitalization because she did not feel threatened or patronized by a health care team that had taken the time to explore feelings and thoughts concerning her illness.

Cultural aspects are variables that are frequently disregarded when, in fact, they may strongly influence an individual's perception of their illness, as in the case presented. Awareness of the cultural background of a patient's symptomatology can improve rapport, trust and the eventual outcome of treatment.

\section{ACKNOWLEDGEMENTS}

The author would like to express her thanks and appreciation to Haikaz Grigorian, MD and Cheryl Kennedy, MD for their critical review of this paper. 


\section{REFERENCES}

1. Kaplan HI, Saddock BJ (eds): Synopsis of Psychiatry, 6th ed, Baltimore, Williams and Wilkins, 1991

2. Koss JD: Expectations and outcomes for patients given medical health care or spiritist healing in Puerto Rico. American Journal of Psychiatry, 1987; 144:1, 56-61

3. Hohmann AA, Richeport M, Marriott BM, Canino GJ, Rubio-Stipec M, Bird H: Spiritism in Puerto Rico; Results of an island-wide community study. British Journal of Psychiatry 1990; 156:328-335

4. American Psychiatric Association: Diagnostic and Statistical Manual of Mental Disorders (Third Edition-Revised). Washington, D.C., American Psychiatric Association, 1987

5. Harwood A: Rx: Spiritist as needed: A study of Puerto Rican community mental health resource. New York, Wiley, 1977

6. Nunez MA: Therapeutic and preventive functions of Puerto Rican Espiritismo. Homines $1990 ; 13: 267-276$

7. Guarnaccia PJ, Parra P, Deschamps A, Milstein G, Argiles N: Si Dios Quiere: Hispanic families' experiences of caring for a seriously mentally ill family member. Culture, Medicine and Psychiatry 1992; 16:187-215

8. Guarnaccia PJ, Good BJ, Kleinman A: A critical review of epidemiological studies of Puerto Rican mental health. American Journal of Psychiatry 1990; 147:11,1449-1456

9. Kroll J, Sheehan W: Religious beliefs and practices among 52 psychiatric inpatients in Minnesota. American Journal of Psychiatry 1989; 146:1,67-72 